\title{
Patient-reported Remission in Rheumatoid Arthritis
}

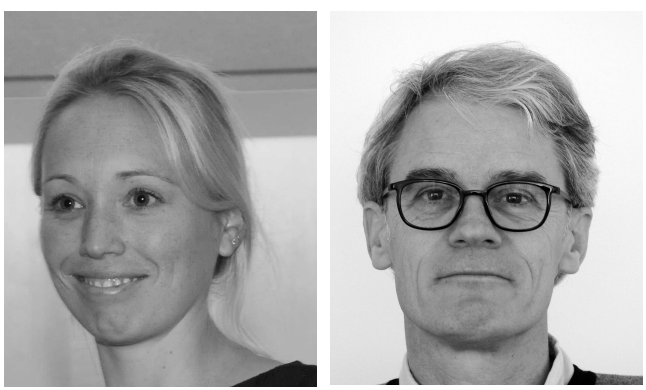

In 2010 , remission was redefined ${ }^{1}$. The set of 4 proposed criteria -2 clinical trial criteria and 2 clinical practice criteria - have since been the subject of several validation studies. Rheumatology researchers have shown that clinical trial criteria requiring a tender joint count, swollen joint count, C-reactive protein (CRP) and patient global assessment $\leq 1$ or a Simplified Disease Activity Index $(\mathrm{SDAI}) \leq 3.3$ perform well in both trial and clinical-practice settings $2,3,4,5,6$.

Fewer data are available on the performance of the practice-based criteria, which exclude the CRP criterion to increase feasibility. Shahouri, et al reported good agreement between the trial and practice-based criteria, and both Lillegraven and Zhang reported comparable predictive validity of the practice-based criteria in observational datasets as compared to trial datasets from which they were developed ${ }^{2,3,6}$.

Reported prevalence rates of remission according to the new criteria range between $5 \%$ and $25 \%$,3,4,5,6,7,8,9, a marked decline compared to reported DAS-based remission rates between $25 \%$ and $50 \%$, and even one instance of $90 \%{ }^{10}$. We now refer to Disease Activity Score (DAS)-based remission as minimal disease activity.

Despite these developments, there are some concerns with the new criteria, especially regarding the requirement of patient global assessment $(\mathrm{PtGA}) \leq 1$. Both Masri, et al and Studenic, et al independently report that the PtGA requirement decreases the specificity of the criteria, especially with the report of noninflammatory problems like low back pain, contributing to false-negative cases ${ }^{11,12}$; this is a valid concern, since it is not desirable that patients with RA, who have problems due to other conditions, are by definition not in remission due to a high PtGA. However, this may be a problem of wording or lack of sufficient instruction of the PtGA tool. Patients may be able to distinguish between RA and other conditions when they are not feeling well, but wording such as "all the ways your arthritis affects you" is hardly specific and in fact invites the patient to report symptoms related to structural disability or mood disorders within the $\mathrm{PtGA}^{13}$. So how best to incorporate the patient perspective on remission in our definitions?

This issue of The Journal includes 2 articles that study the performance of patient-based remission criteria compared to the American College of Rheumatology/ European League Against Rheumatism (ACR/EULAR) remission criteria: 1 based on the Rheumatoid Arthritis Disease Activity Index-5 (RADAI-5) by Rintelen, et al ${ }^{14}$ and 1 based on the Routine Assessment of Patient Index Data 3 (RAPID3) by Castrejon, et $a l^{15}$.

The RADAI-5, developed by Austrian colleagues in search of a fast, easy tool for disease activity assessment in busy clinical-practice settings, is an index comprising 5 questions on a numerical rating scale to be completed by the patient ${ }^{16}$. This shorter alternative for the original RADAI, without the need for joint counts or laboratory values, correlates with the DAS-28, SDAI, and Clinical Disease Activity Index, and, as reported in this issue, shows reasonable agreement with the ACR/EULAR trial-based remission definitions. Of interest is the prerequisite of the RADAI-5 remission-like state, which requires patients to value their own disease activity state as "excellent" before being classified as in remission. Moreover, the RADAI-5 includes a question on arthritis activity over the past 6 months, thus incorporating duration in its definition.

Although the specificity of the RADAI-5 criterion for remission with ACR/EULAR remission is high, the face validity is questionable, with a possible range of tender joint counts from 0 to 7 (mean 0.48 ) and a range of swollen joint counts between 0 and 9 (mean 0.92). However, that is the price to pay for a completely patient-reported tool without joint counts or laboratory assessments.

Castrejon, et al present data on performance of 5 possible RAPID3-based remission criteria. RAPID3 is a patient-reported disease activity index developed from the

See: RA remission criteria instruments, page 386 and 394 
Multidimensional Health Assessment Questionnaire by Pincus, et $a l^{17,18}$, containing 3 commonly collected patient-reported outcomes (PRO) of the RA core set: physical functioning, pain, and patient global estimate. The RAPID3 provides a rapid assessment of disease status as perceived by the patient and, due to the use of core set variables, is highly feasible in any setting. Of the 5 possible remission criteria based on the RAPID3 that were investigated, 4 criteria showed good performance against the ACR/EULAR criteria: all 4 required an additional "careful joint examination" (rather than a formal joint count) and/or a physician global assessment (PhGA). The RAPID3 criterion that most closely resembles the ACR/EULAR criteria for remission is the remission/swollen joint criterion RAPID3R+SJ1: a RAPID3 index $\leq 3.0$ in combination with a swollen joint count $\leq 1$. Unfortunately, ranges of residual disease activity measures are not provided, but the limitation of a swollen joint count $\leq 1$ is an important contribution to face validity. It remains unclear what a careful joint examination constitutes as opposed to a formal joint count; and to what extent these 2 would provide the same results. However, the current study used a formal 28-joint count as collected in the ESPOIR cohort, so there can be no confusion as to what the maximum of 1 swollen joint in the RAPID3 remission criterion means.

These (mostly) patient-reported remission criteria are without question a valuable contribution to RA remission literature, and are especially practical in settings where logistics of laboratory data cause delays or in which formal joint counts are not feasible. In particular, the RAPID3R+SJ1 closely resembles the ACR/EULAR remission criteria. The RADAI-5 is attractive as it is completely patient-based, but can therefore not guarantee face validity in terms of residual disease activity, which is more like the RAPID3 without addition of the swollen joint requirement.

But what can we learn from these data with regard to patient-reported measures in the ACR/EULAR remission definition?

PtGA and pain are PRO that have been shown to contribute important information to defining a patient in remission, independently of assessor- or laboratory-based clinical measures ${ }^{1}$. Because of the strong correlation between PtGA and pain, only PtGA was included in the ACR/EULAR definition. However, no other PRO, apart from physical functioning, were available in the validation phase of this definition. The proposed RAPID3 remission criteria include a measure of physical functioning, but this was deliberately not the case for the ACR/EULAR remission definition; although one of the most important aspects of a patient's quality of life, physical functioning is a measure of both disease activity (mainly in the beginning of the disease or during flares) and of longterm outcome. It was therefore decided to validate the remission criteria against longterm outcomes physical functioning and radiological progression, rather than to include them in the definition. Including a measure of physical functioning within remission criteria could make the results hard to interpret and might require different cutoff points in early versus late disease. It would be interesting to see whether it is possible for patients with considerable structural damage but no disease activity to achieve RAPID3 remission.

Both the RADAI-5 and RAPID3 use a measure of PtGA; however, due to the nature of indexes, they are more flexible with the cutoff point, as is the SDAI. The prerequisite of RADAI-5 remission, where a patient has to rank his/her own disease state as "excellent" before becoming eligible for remission seems very elegant; it would be interesting to see more data on the influence of this prerequisite.

There is a clear need for additional data on the performance of different (combinations of) PRO in relation to remission in RA. This might require the development of new PRO, since remission is still a rather new goal of treatment, and knowledge on the patients' perspective on remission is absent. We are currently investigating how patients experience remission and which aspects of this favorable disease state are most profound to them ${ }^{19}$. This might help us to fine-tune the concept of remission in RA and work towards outcome measures for remission in RA that are both specific and sensitive.

LILIAN H.D. van TUYL, PhD, Department of Rheumatology; MAARTEN BOERS, $\mathrm{MD}, \mathrm{PhD}$, Department of Clinical Epidemiology, VU University Medical Center, Amsterdam, The Netherlands

\section{REFERENCES}

1. Felson DT, Smolen JS, Wells G, Zhang B, van Tuyl LH, Funovits J, et al. American College of Rheumatology/European League Against Rheumatism provisional definition of remission in rheumatoid arthritis for clinical trials. Ann Rheum Dis 2011;70:404-13.

2. Lillegraven S, Prince FH, Shadick NA, Bykerk VP, Lu B, Frits ML, et al. Remission and radiographic outcome in rheumatoid arthritis: Application of the 2011 ACR/EULAR remission criteria in an observational cohort. Ann Rheum Dis 2012;71:681-6.

3. Shahouri SH, Michaud K, Mikuls TR, Caplan L, Shaver TS, Anderson JD, et al. Remission of rheumatoid arthritis in clinical practice: Application of the American College of Rheumatology/European League Against Rheumatism 2011 remission criteria. Arthritis Rheum 2011;63:3204-15.

4. Thiele K, Huscher D, Bischoff S, Spathling-Mestekemper S, Backhaus M, Aringer M, et al. Performance of the 2011 ACR/EULAR preliminary remission criteria compared with DAS28 remission in unselected patients with rheumatoid arthritis. Ann Rheum Dis 2012; E-pub ahead of print.

5. Sakellariou G, Scire CA, Verstappen SM, Montecucco C, Caporali $\mathrm{R}$. In patients with early rheumatoid arthritis, the new ACR/EULAR definition of remission identifies patients with persistent absence of functional disability and suppression of ultrasonographic synovitis. Ann Rheum Dis 2013;72:245-9.

6. Zhang B, Combe B, Rincheval N, Felson DT. Validation of

$$
\text { Personal non-commercial use only. The Journal of Rheumatology Copyright (c) 2013. All rights reserved. }
$$


ACR/EULAR definition of remission in rheumatoid arthritis from RA practice: The ESPOIR cohort. Arthritis Res Ther 2012;14:R156.

7. de Punder YM, Fransen J, Kievit W, Houtman PM, Visser H, van de Laar MA et al. The prevalence of clinical remission in RA patients treated with anti-TNF: Results from the Dutch Rheumatoid Arthritis Monitoring (DREAM) registry. Rheumatology 2012;51:1610-7.

8. Hirabayashi Y, Ishii T. The DAS28-ESR cutoff value necessary to achieve remission under the new Boolean-based remission criteria in patients receiving tocilizumab. Clin Rheumatol 2012 Oct 23; E-pub ahead of print.

9. Kuriya B, Sun Y, Boire G, Haraoui B, Hitchon C, Pope JE, et al. Remission in early rheumatoid arthritis - A comparison of new ACR/EULAR remission criteria to established criteria. J Rheumatol 2012;39:1155-8.

10. van Tuyl LH, Lems WF, Voskuyl AE, Kerstens PJ, Garnero P, Dijkmans BA, et al. Tight control and intensified COBRA combination treatment in early rheumatoid arthritis: $90 \%$ remission in a pilot trial. Ann Rheum Dis 2008;67:1574-7.

11. Masri KR, Shaver TS, Shahouri SH, Wang S, Anderson JD, Busch $\mathrm{RE}$ et al. Validity and reliability problems with patient global as a component of the ACR/EULAR remission criteria as used in clinical practice. J Rheumatol 2012;39:1139-45.

12. Studenic P, Smolen JS, Aletaha D. Near misses of ACR/EULAR criteria for remission: Effects of patient global assessment in Boolean and index-based definitions. Ann Rheum Dis 2012;71:1702-5.

13. van Tuyl LH, Boers M. Patient's global assessment of disease activity: What are we measuring? Arthritis Rheum 2012;64:2811-3.
14. Castrejón I, Dougados M, Combe B, Guillemin F, Fautrel B, Pincus T. Can remission in rheumatoid arthritis be assessed without laboratory tests or a formal joint count? Possible remission criteria based on a self-report RAPID3 score and careful joint examination in the ESPOIR cohort. J Rheumatol 2013;40:386-93.

15. Rintelen B, Sautner J, Haindl B, Mai M, Brezinschek HP, Leeb B. Remission in rheumatoid arthritis: A comparison of the 2 newly proposed ACR/EULAR remission criteria with the Rheumatoid Arthritis Disease Activity Index-5, a patient self-report disease activity index. J Rheumatol 2013;40:394-400.

16. Leeb BF, Haindl PM, Maktari A, Nothnagl T, Rintelen B. Patient-centered rheumatoid arthritis disease activity assessment by a modified RADAI. J Rheumatol 2008;35:1294-9.

17. Pincus T, Yazici Y, Bergman M. Development of a multi-dimensional health assessment questionnaire (MDHAQ) for the infrastructure of standard clinical care. Clin Exp Rheumatol 2005;23 Suppl 39:S19-S28.

18. Pincus T, Swearingen CJ, Bergman M, Yazici Y. RAPID3 (Routine Assessment of Patient Index Data 3), a rheumatoid arthritis index without formal joint counts for routine care: Proposed severity categories compared to disease activity score and clinical disease activity index categories. J Rheumatol 2008;35:2136-47.

19. van Tuyl LH, Smolen JS, Wells GA, Scholte-Voshaar M, Hoogland $\mathrm{W}$, Boers M. Patient perspective on remission in rheumatoid arthritis. J Rheumatol 2011;38:1735-8.

J Rheumatol 2013;40:350-2; doi:10.3899/jrheum.130098 